Mappemonde

Revue trimestrielle sur l'image géographique et les

formes du territoire

$121 \mid 2017$

Varia

\title{
À la recherche du piémont géographique : focus sur une carte du réseau Altibus
}

\section{Anthony Merle}

\section{OpenEdition}

\section{Journals}

Édition électronique

URL : http://journals.openedition.org/mappemonde/3757

DOI : $10.4000 /$ mappemonde.3757

ISSN : 1769-7298

\section{Éditeur}

UMR ESPACE

Référence électronique

Anthony Merle, «À la recherche du piémont géographique : focus sur une carte du réseau Altibus », Mappemonde [En ligne], 121 | 2017, mis en ligne le 01 juillet 2017, consulté le 15 septembre 2020. URL : http://journals.openedition.org/mappemonde/3757

Ce document a été généré automatiquement le 15 septembre 2020

\section{(c) (1) (2)




\title{
À la recherche du piémont géographique : focus sur une carte du réseau Altibus
}

\author{
Anthony Merle
}

\section{Références de la thèse}

MERLE A. (2015). Le piémont géographique : essai pour une approche au prisme des interspatialités : étude croisée entre terrains alpin (Alpes franco-suisses) et carpatique (Roumanie). Thèse de doctorat en géographie, Université Savoie Mont Blanc.

1 Si la montagne est un objet qui n'a cessé d'accompagner la discipline géographique et ses évolutions, la question des seuils de la montagne est toujours restée relativement marginale. Les nombreux concepts qui animent et renouvellent la discipline (interspatialités, intermédiarités...) peuvent être l'occasion de reconsidérer et de réinterroger ces espaces flous, au seuil de «l'espèce d'espace » ou catégorie spatiale qu'est la montagne. Ainsi, en se détachant d'une approche strictement physicotopographique, le piémont peut devenir cet espace sur lequel se déploie un ensemble de fonctions dites « piémontines ». Le piémont n'est plus un donné, figé et immuable, il devient un espace-support, flou et évolutif.

2 Une de ces fonctions piémontines peut être celle de "porte » : le piémont devient ainsi l'espace des «pieds de traversée » (Sutton, 2011) et des "pieds de montée ». Au sujet des « pieds de montée ", l'étude du réseau Altibus se révèle particulièrement pertinente. Née d'une coopération de plusieurs compagnies d'autocars, Altibus est une plateforme de réservation de billets d'autocars à destination des stations de ski des Alpes du Nord. Les clients sont ainsi pris en charge dès leur sortie du train, de l'avion ou d'un autre autocar pour être transportés dans les stations d'altitude. La carte ci-dessous montre que les points de rupture de charge sont tous situés à basse altitude, de la plaine lyonnaise aux fonds de vallées en passant par les villes du sillon alpin. Ces points constituent donc des " pieds de montée ", c'est-à-dire les derniers points de rupture de charge avant l'espace et le temps de la montée en altitude. Cette carte constitue 
également une proposition pour une autre définition cartographique de la montagne, qui n'est plus une « zone » ou une « région », mais un ensemble de points. Ceci n'est pas sans rappeler le postulat de Kevin Sutton (2011) qui se refuse de définir et de délimiter les Alpes par des limites externes de massifs, préférant désigner la montagne par ses lignes de hauteur. Par ailleurs, d'autres cartes montreraient que certaines de ces villes ont également le statut de "pieds de traversée ", c'est-à-dire constituant les derniers points de rupture de charge avant la traversée (et l'erfacement ?) de la montagne.

Figure 1. Carte du réseau Altibus ou la rupture de charge du « Pied de Montée » comme fonction piémontine

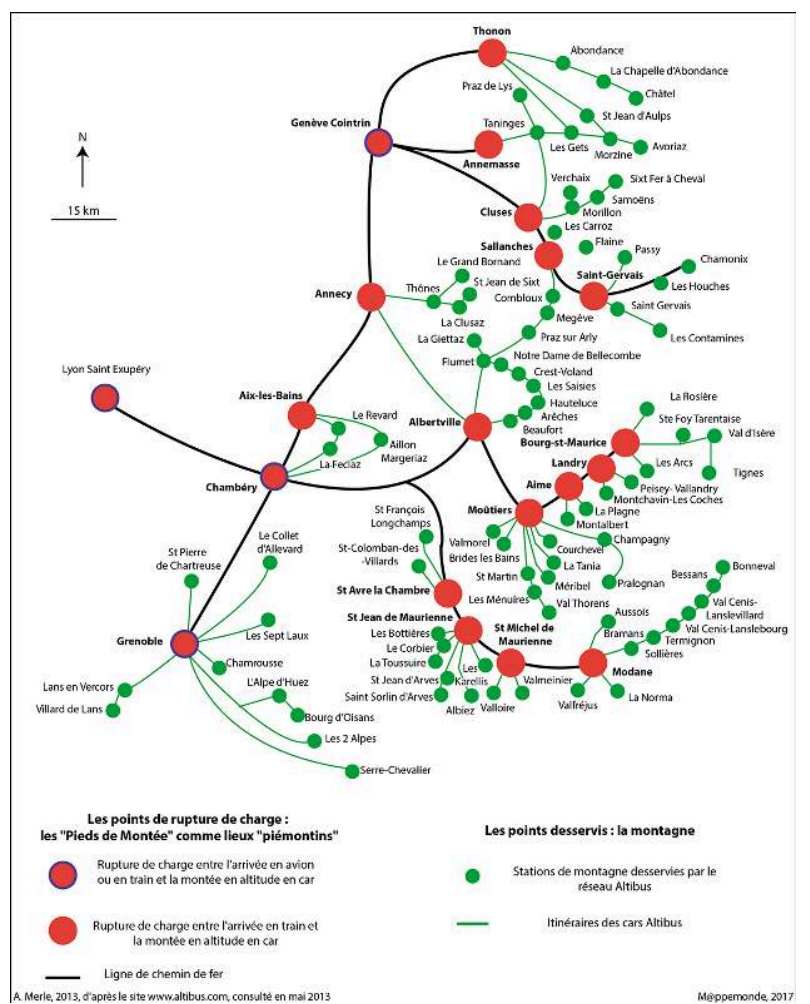

Outre la fonction «porte », le piémont peut se caractériser par sa fonction «vitrine » : il devient ainsi l'espace intermédiaire de mise en contact des acteurs liés à la montagne entre eux et avec les acteurs "non-montagne ». Cette fonction vitrine se matérialise par l'organisation de salons, manifestations et autres congrès, mais aussi par la présence de "maisons de la montagne", de parcs industriels dédiés aux acteurs «montagne »... Altibus, basée à Chambéry, fait partie de ces acteurs, appelés aussi intermédiateurs puisque mettant en contact par leur activité deux réalités sociales et spatiales distinctes. Enfin, la fonction "théâtre " peut également caractériser le piémont qui devient alors cet espace de visibilité, de représentation et de mise en scène d'acteurs définis comme « montagnards».

Évidemment, ces fonctions sont susceptibles de changer de localisation au cours du temps et, dans le cas alpin, une extériorisation croissante de ces fonctions vis-à-vis du massif montagneux a déjà été largement mise en évidence (Bernier, 2005 ; Sutton, 2011). Ainsi, il n'est pas rare que certaines fonctions piémontines se déploient jusque dans des métropoles très éloignées du massif alpin, par exemple jusque Paris (festival "Montagne et musique» de Palaiseau, antenne permanente de Savoie Mont-Blanc Tourisme à Paris...) ou Bruxelles (bureaux de l'association européenne des élus de 
montagne...). A contrario, certaines activités de ces mêmes acteurs - ou intermédiateurs - se déploient au sein même du massif montagneux, comme en témoignent par exemple les assemblées générales de l'association européenne des élus de montagne qui se déroulent souvent dans des lieux clairement considérés comme en et de montagne (Le Grand-Bornand en 2013).

5 Tout cela donne donc au piémont un caractère non figé, éphémère, mais qui ne saurait pour autant éclipser de possibles trajectoires territorialisantes. Les fonctions piémontines deviennent alors sources de concurrence entre certains territoires qui souhaitent les accaparer pour en profiter et gagner ainsi en urbanité et en métropolité. Cela est notamment le cas pour des villes - telles Chambéry - qui peinent à trouver leur place dans le « concert métropolitain » régional, national ou international et qui, par le développement d'une «spécificité piémontine » espèrent profiter d'une logique de « compensation hiérarchique » (Giraut et Chéry, 2000).

Une question reste alors en suspens : tous les processus mis en évidence jusque--là (notamment l'extériorisation et la métropolisation des fonctions piémontines) sont-ils spécifiquement alpins ? Une étude croisée avec un autre terrain (Carpates roumaines) devient alors particulièrement porteuse de sens : l'explication - au moins partielle des décalages observés entre les deux terrains obligera alors à s'aventurer vers d'autres horizons, tels que les décisions politiques ou les contextes historico-culturels.

\section{BIBLIOGRAPHIE}

BERNIER X. (2005). « Les transports en montagne, le bout du tunnel ? ». http://cafe-geo.net GIRAUT F., CHERY J.-P. (2000). « Bassins de coopération intercommunale et hiérarchie urbaine. Les enseignements rhône-alpins ». In MATTEI M.-F. ET PUMAIN D. (dir.), Données urbaines, Paris : Anthropos, coll. «Villes », n 3, p. 27-33.

SUTTON K. (2011). Les Nouvelles Traversées alpines : entre cospatialité de systèmes nationaux et recherche d'interspatialités, une géopolitique circulatoire. Thèse de doctorat, dir. Bernier X., Université de Grenoble, 577 p.

\section{INDEX}

Mots-clés : prix de thèse, prix de thèse 2016 